\title{
A reificação da formação docente diante da onipresença das competências
}

\author{
André Luiz de Oliveira Fagundes* \\ Amarildo Luiz Trevisan ${ }^{* *}$
}

\section{RESUMO}

\begin{abstract}
O texto a seguir situa-se na perspectiva da Filosofia da Educação, tendo como referencial teórico o contributo dos estudos sobre reificação e reconhecimento social, de Axel Honneth. Desse modo, o objetivo é elucidar as relações existentes entre a reivindicação da prática na formação docente, empreendida pelas últimas reformas do campo educacional, e as possíveis manifestações da reificação no processo educativo, bem como estudar possibilidades da apresentação de proposições alternativas inspiradas na ideia do reconhecimento do outro. A proposta empenha-se em responder às seguintes perguntas: em que sentido a legislação oficial da formação docente (alusiva aos professores da escola básica), baseada na concepção de competências, conflui para a manifestação de processos de reificação? Como pode ser pensado um redirecionamento na perspectiva do reconhecimento intersubjetivo?
\end{abstract}

Palavras-chave: Competências. Formação docente. Filosofia da Educação. Reificação. Reconhecimento.

\section{A formação docente inserida no bojo das reformas do campo educacional}

As últimas transformações ocorridas no campo educacional, especialmente na legislação, têm indicado que a educação no Brasil vive um momento histórico de apelo à prática, marcado pela onipresença das competências. O problema, porém, é que isso se dá por meio de uma secundarização da teoria, sobretudo quando se fala em formação de professores. O Parecer CNE/CP 009/2001 é um indicativo de que a prática ou a experiência com a participação e observação no âmbito da escola

\author{
Recebido: 25/08/2013 - Aprovado: 18/11/2013 \\ http://dx.doi.org/10.5335/rep.v21i1.3876
}

Mestre em Educação pela Universidade Federal de Santa Maria (UFSM)/RS. Doutorando no Programa de Pós-Graduação em Educação pela mesma instituição. E-mail andrelive@bol.com.br.

** Doutor em Educação pela Universidade Federal do Rio Grande do Sul (UFRGS). Professor associado III dos cursos de licenciatura e do Programa de Pós-Graduação em Educação (mestrado e doutorado) da UFSM/RS. E-mail: trevisanamarildo@gmail.com. 
constitui uma proposta de reversão de um currículo de formação de professores baseado na ênfase em temas teóricos. Decerto, a reivindicação do contexto real de trabalho é o manancial testemunhador da prática; no entanto, o que questionamos, nessa abordagem, é a ausência do reconhecimento do espaço da prática, também, como locus privilegiado da aprendizagem teórica do conhecimento.

Subjacente à legislação educacional, no que se refere a questões histórico-filosóficas de fundo, é possível perceber a clara preocupação dos organismos oficiais de que é chegado o momento de transpor a herança da tradição ibérica, expressa na oratória e no estudo das humanidades, que ficaram arraigadas no sistema de ensino, e alcançar uma educação de cunho mais pragmático, assentada em processos tecnológicos e operacionais do saber-fazer. No entanto, já na década de 1980, Rouanet (1989) criticava a perda das humanidades, nos currículos escolares, em benefício do atrelamento dos fins da educação ao pensamento tecnocrático e desenvolvimentista, pois ele acreditava que a área das humanidades tinha o potencial de resguardar e auxiliar o pensamento crítico. O que estava em voga, naquele momento histórico da educação brasileira, era, ainda, os efeitos do acordo MEC-USAID, que também resultou na reforma do ensino de $1^{\circ}$ e $2^{\circ}$ graus (5.692/71), na qual estava em ênfase a chamada "pedagogia dos objetivos" - dos domínios: cognitivos, afetivos e psicomotores (BLOOM, 1976). Essa era, também, uma pedagogia que, ainda que um pouco distante, mantinha um vínculo com as teorias de eficiência social, as quais encontram apoio nas linhas de pensamento do taylorismo, justamente por sua afinidade com a psicologia comportamental. Podemos afirmar que esses procedimentos educacionais são bastante similares ao modus operandi da chamada "pedagogia das competências". Isso quer dizer que ainda hoje continua a reversão dos currículos das humanidades para os de cunho mais cientificista. Em decorrência, é natural a perda de espaço e reconhecimento da área dos fundamentos da educação para as áreas procedimentais de atuação metodológica e, portanto, uma hipostasia da prática por um deficit da teoria. Na formação de professores, a institucionalização da prática como componente curricular (PCC - Resolução CNE 1/2002 e CNE 2/2002) segue a direção de apropriação do campo da prática como espaço de formação, porém, equaciona de forma insatisfatória a relação teoria e prática, na medida em que não oportuniza nem apresenta formas de trabalho em que se possa estabelecer reciprocidade e vínculo pertinente entre as disciplinas dos fundamentos da educação com as metodologias da educação.

A reversão de um logos teorizador que se espraiou historicamente nos currículos da área das humanidades passa, inevitavelmente, nessa perspectiva de entendimento, pela necessidade de privilegiar, de ora em diante, o primado da prática, em especial nas questões referentes ao processo formativo daqueles que ensinam. Assim, a hipótese de elevação dos índices da educação básica está situada, 
em boa parte, no modelo de formação docente. Desse modo, é preciso haver uma inversão que passa do postulado teórico à fixação da prática entendida no sentido de melhor conhecer os mecanismos de operação do currículo. "A mudança nos cursos de formação inicial de professores terá de corresponder, em extensão e profundidade, aos princípios que orientam a reforma da educação básica, mantendo com esta sintonia fina" (MELLO, 2000, p. 101). Podemos dizer que, por trás do discurso oficial da educação, está presente a ideia de que os baixos rendimentos dos alunos da escola básica ligam-se "visceralmente" à formação de professores centrada em conhecimentos excessivamente teóricos, abstratos e humanistas, destituídos de uma âncora na realidade concreta do trabalho em sala de aula.

A reversão dessa questão tem procurado situar boa parte dos currículos da escola básica nas chamadas "matrizes de referências", configuradas a partir da ideia de competência, referida à ênfase na prática, anunciada por Perrenoud (1999). As matrizes constituem mecanismos de controle e parâmetros de mensuração para os processos avaliativos externos como o Saeb, a Prova Brasil e o Enem. Por isso, "a definição de currículos/diretrizes nacionais, em termos de competência, tem-se complementado com o estabelecimento de sistemas de avaliação" (MACEDO, 2000 p. 12). Daí que a educação passa a ser discutida no horizonte da comensurabilidade dos dados empíricos. Essa questão diz respeito direto à formação docente, pois todos os professores em formação inicial ou em atuação na escola básica irão se deparar com as exigências de trabalho a partir dessa perspectiva. É possível dizer que tais questões, ora discutidas, representam uma vindicação da prática. Essa apelação teve origem, de certa forma, também, num entendimento equivocado da legislação sobre a continuidade da compreensão moderna do conhecimento no cenário contemporâneo -, na medida em que, ao lutar pelo primado da prática, enfraqueceu-se a teoria.

Nessa mesma linha, a cognoscibilidade condicionada pelo desenvolvimento de competências responde aos anseios de uma nova sociologia laboral, que requer o aprimoramento de habilidades intelectivas operacionais. Essa questão liga-se com a preocupação de se criarem novas práticas de gerenciamento de recursos humanos suscitadas pelo advento de uma outra configuração produtiva, muito próxima do foco de interesse da gestão de empresas. Nesse caso, o que está sendo exigido não é mais somente as forças produtivas físicas, mas, sobretudo, as capacidades neurais afinadas às novas necessidades do mundo do trabalho. Dessa forma, o que está posto pela perspectiva das competências, de modo geral, na educação, no que tange a questões antropológicas de fundo, diz respeito a reforçar, exclusivamente, a imagem ideal do homo faber e, logo, reduzir a complexidade da natureza humana a um único aspecto. 
Por isso, a apropriação que o postulado das competências faz da teoria é de natureza essencialmente explicativa. Isto é: a teoria em educação passa a ser destituída de sua base compreensiva para ser alocada nos mesmos moldes das ciências naturais, em termos de comensurabilidade. Esse equívoco não seria um forte indicativo da ocorrência de uma abordagem instrumental e positivista, dado que a teoria, no campo pedagógico, liga-se, antes de tudo, ao horizonte ontológico e axiológico, e não a questões epistemológicas voltadas à mensuração de resultados do desempenho cognitivo? Inegavelmente, com as devidas proporções, essa questão é evidente nos processos de avaliação externa, no momento em que os indicadores de testes avaliativos como o Saeb, o Enem e a Prova Brasil passam a ser o fim último do empreendimento formativo-educacional das instituições de ensino.

É justamente nessas condições que podemos falar de um esquecimento da teoria em seu aspecto social. Ora, será que podemos afirmar que essa situação também tende a primar pela formação de professores "treinados" para realizar uma educação que se afasta da concepção crítica, uma vez que há pouco espaço para a reflexão sobre a totalidade da formação humana em sua diversidade e singularidade? Quando se fala em "educação por competências", sobre o que exatamente se está falando que esteja além do desenvolvimento de capacidades cognoscitivas que podem ser acionadas em situações específicas de utilidade prática? ${ }^{1}$ Assim, se num sentido amplo é considerada um "devir" (GADAMER, 1997), como a formação pode se encerrar no momento em que são consolidadas as ditas competências?

A ênfase no aspecto da prática, enquanto ação procedimental, cujo carro-chefe parte das propostas formativas da docência endereçadas à educação básica, não estaria enredando o fenômeno educativo num processo de reificação, dado que fica de lado a reflexão teórica que assegura ao professor a compreensão do "outro" para além do enfoque de proeminência cognoscitiva das competências? Diante dessa questão, como pode ser reafirmado o compromisso social da teoria, visto que esse compromisso não se reduz a conhecimentos operacionais, mas se compromete a interpretar, em vista de certos referenciais de dignidade humana, as condições de existência do indivíduo nos grupos sociais? Por isso, pretendemos defender, neste trabalho, que a reflexão teórica da educação precisa evitar o enclausuramento da formação na adoção de competências, para ser pensada nas bases do reconhecimento intersubjetivo do outro. Ultimamente, "a pedagogia contemporânea vê os seres humanos que educa como produtos configurados segundo as expectativas do mercado de trabalho. [...]. Conceitos como mercado, adaptação, performance, produto, se antepõem ao verdadeiro processo de formação do sujeito" (GOERGEN, 2009 , p. 18, grifo do autor). 
Nesse sentido, o grande desafio que paira no cenário da educação contemporânea é a reconciliação das exigências do momento histórico, no qual as questões da esfera produtiva são irrevogáveis, com a garantia de um espaço/tempo destinado à experiência social e à autorreflexão: "o verdadeiro processo de formação humana" (GOERGEN, 2009, p. 18) se amorfiza quando se fecha a possibilidade de a experiência intersubjetiva instituir-se como base do fenômeno educativo. Por isso, a preocupação desmedida com a dimensão epistêmico-profissional e cognoscitiva, como objetivo central, pode gerar a indiferença em relação ao "outro" no processo formativo. Isso não seria já a reificação?

\section{A reificação como "esquecimento do reconhecimento"}

As argumentações de Honneth (2007) indicam que, na nossa relação como o mundo, estamos envolvidos desde sempre com uma atitude de abertura, implicação e interesse, em que paira a "preeminência do reconhecimento sobre o conhecimento", como uma espécie de ímpeto motivador da nossa ação e da nossa capacidade de atribuir sentido e significado às coisas. Essa capacidade prévia de implicar-se com o mundo é de natureza afetiva e emocional. Isso constitui o rudimento que serve de base para uma "apreensão" cognitiva do mundo. Honneth pretende mostrar, buscando apoio em autores da psicologia do desenvolvimento e nos estudos da socialização infantil, sem apelar somente às autoridades filosóficas, que há um estrato de implicação existencial que subjaz a toda nossa relação objetivadora com o mundo. Honneth assinala que o desenvolvimento das dimensões cognitivas está enraizado de maneira bastante peculiar na formação das primeiras relações comunicativas. Pois é justamente aí que, progressivamente, a criança alcança um "descentramento", abandonando a sua própria perspectiva, que inicialmente era egocêntrica.

Honneth coloca que, no desenvolvimento ontogenético, entendido num processo cronológico, o reconhecimento deve preceder ao conhecimento. Daí que no processo de formação individual da criança há a existência de uma identificação crucial com a sua pessoa de referência. $\mathrm{O}$ reconhecimento emocional dá-se antes de se alcançar um conhecimento da realidade objetiva mediante a adoção da perspectiva de uma segunda pessoa (pessoa de referência). $O$ autor esclarece que, provavelmente, Heidegger e Dewey também tinham presente uma ideia de "preeminência", quando defendiam que a relação objetiva e epistêmica com o mundo era precedida por atitude de "cuidado" ou "involucramento existencial". Isso significa que, considerados na sua dimensão mais abrangente e profunda, os esforços cognitivos falham quando se perde de vista o "reconhecimento prévio". Ao passo que em Heidegger o conhecimento científico era derivado da atitude prévia que ele 
denominara de "cuidado", em Dewey toda a investigação tem que estar consciente da sua origem na "experiência qualitativa original" no mundo da vida, que jamais pode esquecer, sob pena de perder de vista esse princípio regulador dos esforços de conquista do conhecimento. $\mathrm{O}$ conhecimento que já não mantém uma linha de ligação com o reconhecimento resvala em reificação.

Honneth acredita ser pertinente trazer para essa discussão (das relações entre conhecimento e reconhecimento) as reflexões de Stanley Cavell, porque este chega a uma ideia própria de reconhecimento ("acknowledgement"). Cavell faz uma crítica ao fato de que podemos obter um conhecimento objetivo, categorial e epistêmico dos estados mentais, do chamado psiquismo alheio. Ao contrário, só se pode alcançar compreensão dessas questões como sujeito envolvido existencialmente que toma conhecimento dos estados de sensibilidade de uma forma não neutra, mas afetado por eles numa relação consigo mesmo. Essa atenção terapêutica na comunicação interpessoal que se faz na intervenção da análise linguística de Cavell sustenta-se, sobretudo, pela implicação mútua. Portanto, o que está em pauta nessa questão é a postura de reconhecimento. Por isso, não temos problemas em entender os pensamentos e sensações de um outro, porque previamente adotamos uma atitude de que os conteúdos de tais pensamentos, enunciados ou sensações nos são dados não de forma estranha, mas natural ou familiar.

As contribuições de Cavell completam o argumento sistemático apresentado por Honneth na discussão sobre a reificação, que ele apresentou proeminentemente, até um dado momento, no seu pequeno livro Reificación: um Studio en la teoria Del reconocimiento, sob o ponto de vista histórico-teórico, com a interpretação das ideias de Lukács, Heidegger e Dewey. Esses, para ele, estavam, pois, convencidos de que o reconhecimento deve preceder ao conhecimento no campo social. E, com as contribuições dos estudos dos autores da psicologia evolutiva, deu-se sustento ao sentido temporal ou genético da questão referente à tese da "preeminência do reconhecimento". Mas foi só recorrendo a Cavell que ele acreditou ser possível defender mais do que o sentido temporal, mas também o sentido categorial e conceitual dessa tese.

Assim, perseguindo as intenções de Lukács num "nível mais alto", Honneth denomina como "reificación" a tal forma del "olvido del reconocimiento" ; y com ello nos referimos al processo por El cual en nuestro saber acerca de otras personas y en el conocimiento de lãs mismas se pierde La conciencia de en qué medida ambos se deben a la implicación y El reconocimiento prévios" (HONNETH, 2007, p. 91). Daí por que o novo conceito chave de reificação esclarecido por ele, ligado à ideia de esquecimento, tem a ver com o fato de que, ao lidarmos com o conhecimento, perdemos a capacidade de perceber e sentir que a sua própria constituição deve-se à adoção de uma "postura de reconhecimento". Por isso, acabamos por desenvol- 
ver a tendência de perceber as outras pessoas como coisas ou objetos insensíveis. Em suma: “La reificación en el sentido de un 'olvido del reconocimiento' significa entonces, en la ejecución del conocer, perder la atención para el hecho de que este conocimiento se debe a un reconocimiento prévio" (HONNETH, 2007, p. 96).

Nesse sentido, pensando essas questões no campo educacional, podemos afirmar que a educação escolar, como fenômeno situado na prática social, mais do que nunca precisa estar atenta para as condições que levam à manifestação de processos reificantes no contexto das relações pedagógicas.

\section{As competências no processo formativo inicial da docência: uma diagnose da reificação}

De um modo geral, desenvolvimento de competências passa a denotar formação de qualidade. É assim que se espraia no corpo da legislação educacional um ensino cuja expressividade atual o coloca como uma espécie de pedagogia oficial. A hegemonia expressa na centralidade desse conceito no discurso das reformas transformou-o no telos da educação institucional. Ele se tornou, ao mesmo tempo, o fím último e o elo articulador que estabelece uma conexão vital entre os princípios formativos da docência em nível superior e as necessidades qualitativas da educação básica, estabelecidas segundo os indicadores das demandas do mercado produtivo.

Com efeito, em vista do exposto, a adesão à perspectiva das competências no campo da formação de professores tem implicações bem pontuais, como: a) enfoque na primazia da dimensão cognoscitiva da formação; b) ênfase na operação prática concreta de trabalho em contrapartida ao enfraquecimento teórico da formação; c) ênfase na consecução de fins alheios às demandas subjetivas do sujeito; e, d) instrumentação das capacidades humanas. Assim, ao se tentar esclarecer o teor das questões filosóficas de fundo que subjazem como pressupostos à superfície do discurso oficial, é possível dizer que, quando as DCNs (BRASIL, 2002) trazem a "linguagem das competências" como o sustentáculo de um tipo específico de educação ou formação de professores, cuja substancialidade reside estritamente no saber fazer e na dimensão cognitivo operacional, há um fechamento da formação sobre si mesma. Logo, a experiência intersubjetiva e as situações que servem de aprendizado do reconhecimento da alteridade do outro ganham pouca atenção ou são tratadas de modo superficial, como elementos secundários, nos textos das propostas oficiais da formação docente.

A problemática dessas questões conflui para a manifestação de um quadro de reificação no processo formativo que concorre para o esquecimento das nossas qualidades substanciais de humanos. Isso se torna mais evidente quando a principal 
motivação das propostas educativas é de cunho instrumental, pretendendo, a todo custo, manter como fím último do processo formativo o vínculo estreito entre educação e necessidades do mercado. Por conseguinte, é deixada de lado a importância fundamental da preeminência do reconhecimento como base dos aprendizados de relações intersubjetivas e ações cognitivas em relação ao mundo. Em decorrência disso, abre-se margem ou espaço para a reificação - manifesta no esquecimento do teor de humanidade, enquanto afeto e identificação com o outro necessário ao desdobramento do ato educativo crítico. Assim, “a intensa reificação mercantilizada da educação formal contemporânea contribuiu decisivamente para o 'esquecimento do reconhecimento' do aspecto especificamente humano na formação das novas gerações" (DALBOSCO, 2011, p. 47).

O Parecer CNE/CP 009/2001 traz “a concepção de competência como nuclear na orientação do curso de formação de professores. Não basta um profissional ter conhecimentos sobre seu trabalho. É fundamental que saiba mobilizar esses conhecimentos, transformando-os em ação" (BRASIL, 2001, p. 29). Transparece, assim, a hipostasiada operacionalidade cognitiva presente ainda no antigo esquema sujeito-objeto. E do mesmo modo fica evidente a ênfase desmedida na dimensão cognitivista em detrimento das outras dimensões da formação. Então, o aspecto cognitivo autonomiza-se, em relação à consideração da pessoa no sentido integral, a ponto de quase ser abordado como um recurso específico ou uma coisa. Decorre daí certa tendência a reificar/coisificar a capacidade intelectiva - esquecendo-a como sendo uma qualidade essencialmente humana, portanto, indo ao encontro de uma situação reificante. Com efeito, “a reificação pressupõe que nós nem percebamos mais nas outras pessoas as características que as tornam propriamente exemplares do gênero humano" (HONNETH, 2008, p. 70).

O primado epistemológico é uma recorrência incisiva presente na tônica do novo discurso da formação de professores: "A constituição das competências é requerimento à própria construção de conhecimentos, o que implica, primeiramente, superar a falsa dicotomia que poderia opor conhecimentos e competências. Não há real construção de conhecimentos sem que resulte, do mesmo movimento, a construção de competências" (BRASIL, 2001, p. 32). Na medida em que concebe e indica o conhecimento como um correlato dependente da noção de competência, o texto do Parecer (CNE, 20001) contribui para quebrar o vínculo do conhecimento com a sua base de "precedência afetivo-emocional", sem a qual realmente ficaria difícil tentar empreender uma educação nos termos do reconhecimento das qualidades de um outro. Se competência é colocada, hierarquicamente, acima do conhecimento, conforme indica o fragmento supracitado, restam poucas chances até para o próprio conhecimento constituir-se nas bases de sua precedência ontológica, na qual, segundo Honneth 
(2007, 2008), reside o "reconhecimento prévio elementar". Em decorrência, tende a instaurar-se uma situação reificada no processo formativo da docência, especialmente na sua relação com o desenvolvimento dos alunos da escola básica, quando é esquecido que o reconhecimento precede o conhecimento ou qualquer tipo de habilidade. Isso ocorre porque a abordagem por competências é destituída de implicação afetiva com aquilo que é apreendido cognitivamente em termos operacionais.

Competência é, também, um mecanismo operacional pelo qual se articula um inventário de objetivos estabelecidos em médio e longo prazo. Não pode ainda ser considerada uma concepção de educação, em sentido amplo, porque, ao firmar-se excessivamente numa forma de operar situado no primado epistêmico/profissional focado hermeticamente na prática concreta, acaba por secundarizar e colocar de lado aspectos vitais do processo formativo, tais como a dimensão afetivo-emocional e a capacidade de implicar-se de modo interessado com a perspectiva do outro. Essas dimensões estão ligadas diretamente a uma base de "reconhecimento prévio e elementar" (HONNETH, 2007), que desde sempre nos constitui ontologicamente como seres capazes de adotar perspectivas de outras pessoas e implicar-se com interesse com os outros, primordialmente por um vínculo afetivo. Essas questões são deixadas de lado à medida que se adota, via legislação educacional, um modelo de formação docente centrado quase exclusivamente no desenvolvimento de competências. Justamente por isso, há uma aproximação cada vez maior com o "el olvido del reconocimento prévio" (HONNETH, 2007, p. 93) - o qual é concebido por Honneth como sendo o núcleo de todos os processos de reificação.

No momento em que o corpus das DCNs (BRASIL, 2002) é, sobremaneira, determinado por um "epistemologismo" prático expresso no enfoque da competência, o locus da formação situa-se no âmbito das capacidades cognitivas operacionais. Com efeito, há um progressivo esquecimento ou afastamento da importância de preservar-se na formação o compromisso por manter vivo aquele "reconhecimento elementar" que desde sempre nos constitui como humanos na nossa autenticidade. Em vista disso, o primado epistemológico que vem, progressivamente, de modo irrefletido, arraigando-se no contexto pedagógico da formação, em especial, pelo caminho da formação de professores, contribui para distorcer o significado "ontológico da mestria" - cuja importância está para além da tarefa de desenvolver competências. Ao contrário, uma ontologia da mestria procura apoiar-se numa base de reconhecimento na qual estão amparadas as relações de confiança e afeto incondicionais. $\mathrm{Na}$ ausência dessa base, não há possibilidade de construir um lastro axiológico de sustento ao conhecimento.

Desse modo, então, se "reconhecer sempre precede conhecer, [...] por 'reificação' devemos entender uma violação dessa ordem de precedência" (HONNETH, 
2008, p. 71). Daí por que a relação professor e aluno não pode se reduzir a competências ou ter o seu significado maior interposto pela necessidade de desenvolver capacidades cognitivo-operacionais destinadas ao atendimento das demandas de mercado. É preciso evitar que o valor imanente da educação seja transferido para a esfera econômica. Por isso, "a educação deveria significar sempre uma crítica à reificação" (DALBOSCO, 2011, p. 48). Nesse sentido, a formação da docência consiste em algo além daquilo que é possibilitado pelo domínio das competências - e que não se encerra no aparato cognitivo.

Enquanto as propostas formativas atuais da docência esquecem-se de enfocar a importância da experiência intersubjetiva para o processo formativo-educacional da humanidade do homem, o valor imanente da educação, constitutivo da relação pedagógica, situado nas relações de reconhecimento, tem sido transferido para a esfera do trabalho econômico. Essa situação não seria o protótipo da rotinização de práticas sociais mediadas pela indiferença e a neutralidade entre as pessoas, e, portanto, a reificação compreendida como o esquecimento daquele reconhecimento prévio? Pois os 'sujeitos podem 'esquecer' ou aprender a negar posteriormente aquela forma elementar de reconhecimento que, em geral, eles manifestam a toda outra pessoa se eles participam continuamente numa forma de práxis altamente unilateral, que torna necessária a abstração das características 'qualitativas' de pessoas humanas" (HONNETH, 2008, p. 75).

Vale destacar que esse aspecto da unilateralidade da práxis é o que sempre caracterizou os fenômenos de reificação como patologia social, de Marx a Honneth. Nesse sentido, o que está em risco constante na abordagem das competências é, em última instância, o estatuto da prática educativa como práxis humana, formativa do ser humano. A chamada pedagogia das competências unilateraliza a práxis e abstrai as características qualitativas dos seres humanos. Portanto, o modelo de formação docente situado nessa perspectiva, olhado pelo prisma honnethiano, induz os agentes a participarem sistematicamente de uma "forma de práxis altamente unilateral", a qual propicia a "abstração das características 'qualitativas' de pessoas humanas". Essa forma de práxis, quando exercida rotineiramente no contexto das instituições formativas, tem nos tornado vulneráveis à reificação intersubjetiva. Daí por que a ideia de reificação como "esquecimento do reconhecimento" pode constituir um aporte teórico balizador de análise das condições de desdobramento do processo educativo na contemporaneidade, sobretudo quando tivermos que pensar a formação inicial da docência e a sua relação com a escola básica. 


\section{A teoria do reconhecimento em Axel Honneth}

O que marca a substancialidade do reconhecimento elementar é o "fato de assumirmos perante o outro uma postura que alcança até a afetividade, postura na qual podemos reconhecer nele o outro de nós mesmos, o próximo" (HONNETH, 2008, p. 72). Apesar de essa forma de reconhecimento estar distante da fronteira a partir da qual já podemos falar de normas e princípios do reconhecimento recíproco, o "reconhecimento prévio elementar" inaugura as bases fundamentais daquilo que constitui as possibilidades do "reconhecimento normativo", sem as quais este não aconteceria.

Portanto, primeiramente precisa ser consumado esse reconhecimento elementar, precisamos tomar parte (Anteilnehmen) do outro existencialmente, antes de podermos aprender a orientar-nos por normas do reconhecimento que nos intimam a determinadas formas de consideração ou de benevolência (HONNETH, 2008, p. 73).

Nesse sentido, se a reificação é a negação ou o esquecimento da capacidade de estabelecer relações intersubjetivas baseadas na afetividade e na identificação com o outro, sustentadas pelo reconhecimento elementar, e se esse é o estágio fundamental de pré-condição para as possibilidades de efetivação do reconhecimento recíproco, orientado por princípios normativos, então, a teoria de Honneth, expressa nos padrões do reconhecimento intersubjetivo, representa, também, uma proposição referencial eficiente contraposta à reificação, porque permite o esclarecimento de uma consciência interpretativa das condições reificadas da vida social, bem como os caminhos das lutas expressos no aspecto moral do conflito social.

A teoria do "reconhecimento intersubjetivo", de Axel Honneth, exposta na sua obra intitulada Luta por reconhecimento: a gramática moral dos conflitos sociais, assenta-se em grande parte naquilo que o jovem Hegel havia traçado em seus estudos de Jena. Honneth explica que em Hegel já era possível identificar rudimentos que poderiam tornar-se o fio condutor de uma teoria social de teor normativo, dado que o propósito de Hegel naquele momento era tornar claros os processos de mudança social, remetendo-se às pretensões normativas estruturalmente inscritas na relação de reconhecimento recíproco. Por isso, a substantividade da ideia de reconhecimento de Honneth procura sustentáculo final no postulado hegeliano de que a formação do eu prático depende do jogo da reciprocidade do reconhecimento ilustrado na luta entre dois sujeitos ou na relação intersubjetiva. Porém, o necessário apoio pós-metafísico à teoria do reconhecimento de Hegel, ele encontra na psicologia social de Mead. Com esse autor, é alcançada uma inflexão materialista para a teoria hegeliana da "luta por reconhecimento". Assim, o que está em jogo na equivalência teórica colocada em evidência por Honneth, nesses dois pensadores, não diz respeito 
somente ao fato de que a formação prática da identidade humana é dependente da experiência de reconhecimento intersubjetivo, como também à distinção conceitual de diversas etapas de reconhecimento mediadas por lutas ou conflitos.

A compatibilização de Mead com Hegel, exposta por Honneth, esclarece, portanto, que a dinâmica de reprodução da vida social efetiva-se sob a tônica de um reconhecimento recíproco, uma vez que os indivíduos só conseguem alcançar uma autorrelação prática na medida em que aprendem a conceber-se sob o ponto de vista normativo de seus parceiros de interação. No entanto, o imperativo que está apoiado no processo de vida social funciona como uma coerção normativa; o filósofo explica que isso obriga os sujeitos a uma deslimitação gradativa do conteúdo do reconhecimento recíproco, pois seria somente por esse meio que eles poderiam atestar uma expressão social às pretensões de sua subjetividade que está sempre a regenerar-se. "São lutas moralmente motivadas de grupos sociais, sua tentativa coletiva de estabelecer institucional e culturalmente formas ampliadas de reconhecimento recíproco, aquilo por meio do qual vem a se realizar a transformação normativamente gerida das sociedades" (HONNETH, 2003, p. 156). Assim, Honneth explica que essa questão foi abordada pelo desenvolvimento da teoria do reconhecimento efetuada por Hegel, desembocando no modelo de conflito. Entretanto, isso se realizou, naturalmente, por vias idealistas, ao passo que Mead o fez de maneira, segundo ele, "materialista". Nesses termos, o autor argumenta que ambos os pensadores, tanto o autor da Realphilosophie, como o pragmatista estadunidense, desenvolvem pontos similares no que se refere a uma tentativa de localizar diversos modos de reconhecimento nas respectivas esferas de reprodução social: enquanto Hegel diferencia a política, a sociedade civil e o Estado, Mead destaca nas relações primárias do outro concreto as relações jurídicas e a esfera do trabalho como duas formas diferentes de realização do outro generalizado.

É na distinção dos três padrões do reconhecimento que Honneth (2003) encontra uma chave teórica para estabelecer uma diferenciação sistemática, distinguindo, com clareza, outros tantos modos de desrespeito. A diferença entres eles é aferida pelos diversos graus que podem afetar a autorrelação prática de uma pessoa, na medida em que ela é privada do reconhecimento de determinadas pretensões de identidade. Honneth explica que é somente a partir dessa subdivisão que se pode dar resposta à seguinte questão (que não foi desenvolvida por Hegel nem por Mead): "Como a experiência de desrespeito está ancorada nas vivências afetivas dos sujeitos humanos, de modo que possa dar, no plano motivacional, o impulso para a resistência social e para o conflito, mais precisamente, para uma luta por reconhecimento?" (HONNETH, 2003, p. 214). Nesse momento, Honneth dá um passo a mais, determinante na teoria do reconhecimento, destacando pontos 
não desenvolvidos pelos seus predecessores. Desse ponto em diante, o autor explica a dinâmica do desenvolvimento da luta por reconhecimento, explorando a ideia de "conflito social" presente no interior das relações interativas; sua referência principal reside na categoria da "experiência de desrespeito social", que tem um efeito direto na estrutura psíquica da pessoa.

A base vital de sua teoria esclarece que, se para cada esfera ou padrão de reconhecimento recíproco, em seus termos positivos, está inscrita na experiência do amor a possibilidade de autoconfiança, na do direito, o autorrespeito e, por fim, na experiência da solidariedade, a da autoestima; em contrapartida, há um correspondente negativo para cada uma dessas experiências de reconhecimento, representados pelas formas de desrespeito. Assim, em cada nível do reconhecimento, tomado isoladamente, podemos encontrar um correspondente negativo, no qual a "experiência de desrespeito social" pode ser esclarecida, tendo em vista a forma de reconhecimento que está sendo degradada ou ofendida, no sentido de privação da “autorrelação positiva" que o indivíduo estabelece consigo mesmo no interior de seu grupo social.

Sendo assim, a primeira esfera de reconhecimento (amor) pode ser afetada por formas de desrespeito que atacam a corporeidade física do sujeito. Na segunda esfera (direito), com a forma de desrespeito correspondente, ocorre a denegação dos direitos; nessas condições, o que está em jogo é a perda do status de igualdade. $\mathrm{Na}$ terceira esfera do reconhecimento (solidariedade), o desrespeito desqualifica o valor individual das pessoas e de determinados grupos sociais; consequentemente, os sujeitos acabam por ser atacados na sua autoestima, na própria imagem que fazem de si mesmos. Por isso, na visão de Honneth (2003), o conjunto das reações negativas que acompanham, no horizonte da estrutura psíquica, a experiência de desrespeito social pode ilustrar, com bastante exatidão, uma base motivacional afetiva em que se assenta a luta por reconhecimento. É por isso que, para Honneth (2003), o sustentáculo de uma concepção de vida boa passa, necessariamente, pela garantia de que, nos processos interativos, o sujeito tenha asseguradas para si as condições fundamentais de sua autorrealização.

\section{Formação docente pensada nos termos da teoria do reconhecimento intersubjetivo}

A partir do contributo teórico honnethiano acerca do reconhecimento recíproco, pretendemos retomar essa categoria para repensá-la como contraposição aos efeitos reificadores no cenário da educação, principalmente quando o assunto é a correlação entre propostas oficiais referidas à formação inicial de professores e 
ao desenvolvimento dos alunos da escola básica. O objetivo é elencar proposições para uma proposta de formação docente inspirada na ideia do reconhecimento intersubjetivo. Entretanto, não queremos, evidentemente, esboçar uma apropriação aplicacionista do postulado teórico social de Axel Honneth no contexto educativo, e menos ainda empreender uma submissão da realidade educacional brasileira às suas categorias. Contrariamente, ao fazermos jus à característica essencialmente reflexiva da Filosofia da Educação, nossa intenção fundamental é tematizar a teoria do reconhecimento como um horizonte no qual as proposições e reflexões para o processo formativo da docência possam encontrar um fundamento relativamente mais seguro, tendo em vista as necessidades da educação no contexto contemporâneo.

Desse modo, apresentaremos, abaixo, quatro problemáticas fundamentais para o campo da formação docente, que são representativas dos efeitos da onipresença das competências, seguidas de proposições alternativas orientadas pelo postulado do reconhecimento recíproco, contrapostas a essas questões:

a) A carência da reflexão, nas licenciaturas e nas políticas de formação, a respeito daquilo que constitui matéria para autorrealização dos educandos da escola básica versus a relação positiva dos educandos consigo mesmos, como objeto de referência para as propostas do campo formativo da docência.

O ideário das competências pretende apresentar para os docentes, tão somente, os meios operacionais do fazer pedagógico que possam desencadear o desenvolvimento da aprendizagem dos alunos. No entanto, tal proposta vale-se desse intento sem considerar o sujeito na sua singularidade, ignorando, portanto, a importância do saber que permite ao professor o conhecimento da forma pela qual o aluno se faz sujeito nos seus processos de interação. Como decorrência desse modo de operar na educação, pouca importância tem para esse tipo de proposta a pergunta sobre em que consiste a autorrealização do aluno da escola básica, em seus diferentes níveis. Salvo a sua relatividade, a pergunta resguarda um ponto crucial para o sucesso do processo pedagógico, pois coloca a centralidade do outro como categoria fundamental para o encaminhamento das condições de ensino e aprendizagem numa outra perspectiva. Nesses termos, podemos dizer que o aluno se saberia identificado nas propostas que lhe são dirigidas, dado que assim estas corresponderiam ao diálogo com seus jogos de linguagem e à contextura de seu mundo cultural e psicossocial, sem descartar a referência de um quadro mais amplo e universal da formação humana.

Ora, se o grau de autorrealização positiva do sujeito intensifica-se na sequência das esferas do reconhecimento (HONNETH, 2003), como poderia a escola, sendo uma das primeiras instituições sociais de peso na constituição da subjetividade, isentar-se de seu compromisso eminentemente social de contribuir, com seus 
meios específicos, no que diz respeito à sensação de assentimento e reconhecimento equitativo para com o indivíduo frente aos seus pares e grupos de socialização no cenário da sociedade mais ampla?

Assim, a partir de uma análise mais focada, é possível compreender que a relação entre a formação inicial da docência e a educação básica, impingida pelos documentos oficiais (BRASIL, 2001, 2002), referentes à formação de professores licenciados, revela que a segunda passa a constituir para a primeira o espaço exclusivo de desenvolvimento de competências, que futuramente poderão ser postas em prática nas mais diversas situações. Logo, nos cursos de formação é enfraquecida a ideia segundo a qual a escola é, desde sempre, um espaço de formação que tem como referência a consideração pela perspectiva do outro e, por isso mesmo, um lugar privilegiado de aprendizagem e vivência do reconhecimento recíproco. $\mathrm{O}$ grande desafio é, então, construir uma nova compreensão da escola, junto ao discurso da formação de professores, que passe do lugar destinado exclusivamente ao desenvolvimento de competências ao lugar de exercício do reconhecimento intersubjetivo.

É preciso sublinhar, no pensamento dirigido à formação docente, que a segurança da qual o educando necessita para o desenvolvimento e uso pleno de suas capacidades não depende somente da ideia de competências, tal como vem sendo defendido pela legislação educacional brasileira. Desse modo, conforme as argumentações de Honneth (2003) de que a possibilidade da autorrelação positiva pode ser ratificada exclusivamente pela experiência do reconhecimento e que de esse fato permite ser entendido como indicação das condições necessárias da autorrealização-individual, podemos dizer que cometem um equívoco as concepções de docência que apostam todas as suas forças em ensinar aos professores os procedimentos operacionais de desdobramentos de uma aula destinada a prover competências situadas em contextos específicos.

Assim sendo, se as configurações das autorrealizações positivas só se fazem pelas vias do reconhecimento, então, "a liberdade da autorrealização depende de pressupostos que não estão à disposição do próprio sujeito humano, visto que ele só pode adquiri-los com a ajuda de seu parceiro de interação" (HONNETH, 2003, p. 273). Daí por que, quando se fala em formação de professores situada nas trilhas do reconhecimento do outro, é preciso ajudar a construir, junto aos formandos em docência, a ideia segundo a qual a atribuição fundamental do professor, no espaço da escola, é cumprida, de forma crítica e ética, na medida em que a função da mestria consiste em: a) reconhecer as circunstâncias nas quais os alunos sentem-se seguros para o uso e a aplicação de seus saberes e capacidades; b) reconhecer as suas diferenças ou singularidades; e, c) reconhecer toda a gama daquilo que constitui objeto de atenção e interesse dos jovens. 
Essas questões, quando consideradas em suas peculiaridades, passam a constituir matéria do pensar e do fazer pedagógico. Entretanto, o papel do professor consolida-se na escola, nos termos do reconhecimento intersubjetivo, somente quando, na sua atuação pedagógica, consegue inserir, juntamente com os alunos, essas questões do universo destes últimos no quadro de referência de uma cultura sistemática e universal, a qual os habilita também a participar, de forma mais efetiva e segura, das lutas sociais e do debate permanente no contexto da esfera pública da sociedade. Por conseguinte, o que pretendemos defender é a extensão da autorrelação positiva do plano da teoria social para o âmbito da reflexão pedagógica consubstanciada na satisfação e autorrealização do educando consigo mesmo no interior da escola, como espaço ou grupo social específico pertencente à sociedade maior. Logo, esse é o imperativo que se precisa instituir como princípio sob o qual se debruçam as reflexões teóricas, destinadas a compor propostas formativas para o campo da docência.

b) Naturalização da onipresença das competências na formação docente, via propostas oficiais versus a valorização do professorado em atuação como grupo específico que, no pensar crítico sobre seu ofício, também produz importantes conhecimentos para o campo educacional.

A nova proposição da formação docente, erigida no bojo da reforma educacional, insere-se num cenário no qual se vem naturalizando a onipresença das competências. Com efeito, aquilo que está posto pela legislação é considerado absolutamente como o que existe de mais sofisticado e qualitativo no campo atual da educação. Daí por que se procura desenvolver e elencar um conjunto de competências docentes antes de consultar a "realidade" das práticas educativas realizadas em diferentes contextos do país. Por isso, há pouca possibilidade de mobilizar a reconciliação com o outro, nesse caso, com os professores da educação básica, em especial com aquilo que historicamente vem sendo realizado de mais produtivo e criticamente positivo no interior das escolas, e não é incluído ou discutido nos documentos oficiais da educação. Afinal, na implantação de um currículo baseado na noção de competências, tudo já deve estar de antemão definido, de forma a priori - o que e como ensinar já é decidido em instâncias alheias à prática que o discurso oficial tanto propaga respeitar. É inegável a coexistência das mais diversas experiências pedagógicas no exercício da docência pelo país afora. Contudo, elas precisam confrontar-se com a teoria, a fim de reforçarem-se formativamente. Só assim poderão fazer frente à onipresença das competências, a qual não hesitará em colonizar esses espaços de vivência da experiência de liberdade educativa. 
No diálogo constante com os formadores de professores e com alunos das licenciaturas em processo de formação inicial, os professores da educação básica abrem margem para a validação de seus conhecimentos nos ambientes da esfera acadêmica científica e, ao mesmo tempo, contribuem com os futuros pares do seu quadro profissional. Essa relação de reconhecimento recíproco somente pode dar-se, efetivamente, num processo de interatividade constante entre a universidade e a escola. Assim, os graduandos, em vez de ficarem restritos a uma formação prescritiva da chamada pedagogia das competências, podem, desde já, ter ideia de um conhecimento que não é categorizável no universo acadêmico, mas é primordial para os processos formativos. Esse tipo específico de conhecimento, de natureza mais tácita ou experiencial, só pode ser percebido, inicialmente, pelo testemunho que o professor de escola básica ilustra a respeito do seu enfrentamento cotidiano com a realidade educativa. É na interação comunicativa que pode residir a possibilidade de reconhecimento normativo das práticas educativas do professor em serviço, no horizonte do debate das políticas públicas de formação de professores.

Contudo, para a valorização dos professores em atuação, na perspectiva do reconhecimento do outro, também não é recomendável a supervalorização de uma suposta essência da docência presente nos seus modos e performances de ação pedagógica cotidiana, desdobradas no espaço da sala de aula, como sendo a verdade última do conhecimento docente. Se assim fosse, isso concorreria para o fechamento da formação a outros graus ontológicos do conhecimento. Precisamos evitar, conforme indica Repa (2010), seguindo os estudos de Honneth, o "reconhecimento como ideologia", o qual procura uma afirmação positiva de certas qualidades e propriedades de determinados grupos sociais, até então depreciados na sua forma de existência, justamente para os manterem, voluntariamente, numa posição subordinada e manipulável. Portanto, no caso específico do grupo social dos professores, seria uma forma de reduzir, intencionalmente ou não, a sua influência na opinião pública e na direção das políticas sociais, quando absolutizam a valorização dos seus saberes restritos à experiência intraescolar.

c) Esquecimento das experiências educativas não coadunadas ao ethos da produtividade econômica versus recondução do valor imanente da educação no esquema do reconhecimento prévio elementar.

A "linguagem das competências" (PERRENOUD, 1999), tal como foi apropriada pela legislação referente à formação docente, tem reduzido a possibilidade de autoesclarecimento dos sujeitos em torno da questão social e do mundo da vida, bem como o diálogo com o outro. Essa questão deve-se à necessidade de trabalhar quase que integralmente em cima da dimensão cognoscitiva, a fim de desenvolver 
determinadas capacidades intelectivas e prático-operacionais. Desse modo, o outro ao qual ela se dirige passa a ser, tão somente, a incidência de sua ação (o mesmo), e não um outro (não-eu) considerado como sujeito também autônomo no processo educativo. O motivo maior do encontro dos sujeitos da relação pedagógica não pode ser justificado, em seu fim último, pela manutenção das práticas sociais requeridas pelas demandas da vida econômica, dado que, ao colocar o valor capital da cognição humana como centralidade e fim máximo a ser buscado pela ação pedagógica, os intentos da reforma educacional, irremediavelmente, acabam por esquecer o valor imanente da educação como prática social substancialmente humana.

Nesse sentido, uma formação docente erigida nos lastros do assentimento intersubjetivo e de estima simétrica precisa ter o compromisso principal de compreender com clareza que é primordial para a educação, em tempos de avanço econômico e evolução tecnocientífica, aprender a propor e desenvolver experiências formativas que se reportem à rememoração daquela forma de reconhecimento existencial, o qual, além de ser a base do reconhecimento recíproco normativo, pode ser considerado o húmus substancial da relação pedagógica de estima mútua e acolhimento da perspectiva do outro. Com efeito, a apreensão cognitiva de qualquer conteúdo ou matéria não se faz sem uma base de precedência afetivo-emocional. Ou seja, a educação precisa auxiliar o sujeito a estabelecer uma "relação de implicação" com o outro e com as coisas do mundo que constituem objetos de estudo a serem aprendidos, do contrário caímos em reificação. O propósito, então, é reconduzir o valor imanente da educação novamente para a realização do sujeito, de modo a evitar que todas as forças educativas voltem-se para o alcance de fins alheios ao processo, muitas vezes situados, por exemplo, nas esferas da previsibilidade da razão instrumental.

d) A recomendação da ideia de uma prática da formação docente enfraquecida de teoria versus reposição da teoria comprometida com a compreensão da dimensão social da vida.

O estado atual ao qual chegou a concepção de formação docente nas instituições formadoras, via discurso da reforma, espraiou, em suas proposições de trabalho, que o grande impasse educacional contemporâneo no Brasil deve-se, sobremaneira, a um deficit de prática, especialmente daquela prática necessária para manusear as técnicas didáticas de condução da aula no termo das competências. Desse modo, a teoria da formação de professores ficou enfraquecida quando submetida ao leque de questões restritas à natureza técnico-didática do ensino. Isso se deve à crença de que os baixos índices de desempenho dos alunos da escola básica atribuem-se, exclusivamente, a questões de aprendizagem. Ainda que, suposta- 
mente, esse fato ilustrasse a totalidade dos problemas em educação, o diagnóstico da reforma comete outro equívoco: tenta-se transpor os obstáculos ao aprendizado pela troca adequada de método, como se existisse uma compatibilidade absoluta entre metodologia e aprendizagem. Prescreve-se, assim, como solução para o hipotético problema, uma educação baseada na ideia de competências. Essas são referidas à prática concreta de ação, ao saber-fazer e incidem, principalmente, na capacidade cognitiva de atuação em termos individualizados. A recomendação de prática, na nova concepção de docência anunciada pela reforma, leva ao enfraquecimento da teoria e da percepção crítica do professor frente à natureza social dos problemas pedagógicos, porque não transpõe as técnicas de ensino.

Agora, se formos pensar a recondução da teoria da formação docente nos termos do reconhecimento, começaremos a compreender a sua importância numa escala de proficiência de maior amplitude na questão educacional contemporânea, primeiramente porque o caráter normativo da teoria compromete-se com o esclarecimento da totalidade do fenômeno educativo. Isto é, por exemplo: a teoria coloca-se para si a pergunta da posição da educação escolar no contexto da sociedade mais ampla. Por ser ilustrativa dos estudos das ciências, a teoria permite ao professor saber a respeito da constitutividade da natureza dos problemas da vida social que desaguam no microcosmo da sala de aula e, por isso mesmo, entender de antemão que o problema pedagógico da escola básica contemporânea não pode ser reduzido a uma questão de uso do método correto. É a teoria, na medida em que informa e dialoga com a prática, que está em melhores condições de dar conta dos desafios atuais do cenário educacional, permeado pelo caráter contingencial das diferenças e das pluralidades culturais, e não o receituário puro da prática, assumido no discurso das competências. Sendo assim, uma prática bem orientada pela teoria e uma teoria bem informada pela prática são sempre diretivas, no sentido de encaminhar essas questões num horizonte mais extenso das manifestações sociais no plano de um universalismo, também sensível às particularidades geográficas e étnico-culturais.

Dessa forma, a teoria assentada no fulcro da proposta do reconhecimento intersubjetivo possibilita ao professor uma compreensão de seu aluno para além do aspecto cognitivista, representativo dos índices da educação escolar. Ou seja, age com seu aluno, antes de qualquer coisa, como um sujeito que só estará em condições de apropriação cognitiva e de implicação com objeto de estudo, se for anteriormente considerado na sua constitutividade afetiva e emocional, sem a qual não há base para o desdobramento do conhecimento. Daí que, na perspectiva da intersubjetividade, a teoria e prática da formação docente podem ser entendidas como duas representatividades do agir social, que para se completar plenamente necessitam 
de uma estrutura relacional nos moldes do reconhecimento mútuo. Com efeito, quando teoria e prática estão assentadas nessa lógica da reciprocidade, é conferido à ação pedagógica um sentido crítico e emancipatório.

A ideia das problemáticas enunciadas acima quer representar, no âmbito da discussão pedagógica, especialmente na área da formação docente, as situações que podem ser descritas no quadro de experiências reificantes e de não reconhecimento, e, por isso mesmo, também figurar um diagnóstico esclarecedor, necessário para reencaminhamento alternativo em direção oposta - principalmente pelos imperativos da teoria do reconhecimento intersubjetivo.

\section{CONCLUSÃO}

Tendo em vista nossos questionamentos iniciais, o objetivo foi abordar o problema da formação de professores no contexto da sociedade brasileira num quadro teórico que liga o tema da reificação ao do reconhecimento normativo. Como propomos uma abordagem da formação docente situada no horizonte de estudo dessa teoria, seguimos as argumentações de Honneth (2003) de que é necessário estabelecer a explicação de uma forma de reconhecimento existencial anterior às formas de assentimento recíproco expressas nos três padrões de reconhecimento, a qual servisse de base para a possibilidade de consolidação do reconhecimento normativo em esferas mais amplas da sociedade. Levando em conta essa questão, exploramos a ideia de autorrelação positiva do sujeito na sequência dos padrões de reconhecimento, como um modo a mais de contribuir para manter segura e viva a continuação da rememoração daquela forma de reconhecimento existencial, a qual nos constitui desde sempre como seres do gênero humano. Como decorrência, assim estaria assegurada uma estratégia teórica, ao mesmo tempo, de reforço de direitos e possibilidade de defesa para evitar os efeitos de manifestações reificantes, também no âmbito da pedagogia.

Um programa de saberes referentes à prática educativa do professor não alcança um status de criticidade emancipadora se não consegue vincular aquilo que constitui objeto específico de estudo dos cursos de licenciatura aos conhecimentos que permitem uma formação teórica num sentido amplo. A dimensão político-filosófica da formação docente não ocorre num espaço de redução da teoria a favor da prática de saberes técnico-didáticos. Considerar a questão da formação de professores no Brasil, pelo viés do reconhecimento, significa compreender os professores como grupo social específico que se constituiu, também, no horizonte das lutas sociais de reivindicação de uma escola pública com qualidade e dos direitos da cidadania.

Conceber outros modelos de formação da docência, sobretudo se considerada a questão do reconhecimento social atualmente, requer, antes de qualquer coisa, um processo formativo no qual os futuros professores possam construir uma concepção 
de escola que tenha por compromisso primeiro valorizar as diferenças e as singularidades sociais. Isso permite aos alunos da escola básica, cujos professores tiveram uma formação pautada por esse tipo de exigência, que desenvolvam, não só no plano cognitivo, como também no afetivo-emocional, o conhecimento de um quadro referencial de análise. Segundo esse dispositivo, os estudantes poderão saber, com certa exatidão, as circunstâncias ou o momento em que são referendadas ou depreciadas suas qualidades e capacidades substanciais de humanos, como cidadãos pertencentes a uma coletividade e portadores de direitos equitativos.

A vivência na sociedade contemporânea plural requer mais do que a assunção das competências no processo educativo. Assim sendo, espera-se do professor um trabalho centrado na esfera intersubjetiva, na qual seus alunos possam experienciar a valorização das diferenças e a afirmação de suas singularidades de maneira plena. A ação docente não pode se reduzir a fins imediatos de aplicação de propostas oficiais, mas precisa, sobretudo, contribuir para efeitos de mais longa duração no destino da realidade social e da inserção crítica do sujeito na vida da sociedade. Daí a necessidade primordial de estruturar o trabalho nos trilhos daquilo que possa constituir reforço para o desenvolvimento da eticidade. O que está em jogo na esfera política da educação não é apenas a elevação dos índices de apropriação cognitiva dos saberes, mas, acima de tudo, o encaminhamento do processo civilizatório endereçado pelo empreendimento formativo-educacional, cujo êxito, inquestionavelmente, depende nos dias atuais, em grande parte, da formação de professores, numa compreensão crítica e intersubjetiva da educação.

\section{The reification of teacher formation up against the omnipresence of competences}

\section{Abstract}

The following text isfound under the perspective of Philosophy of Education, having as its theoretical reference the contribution of studies about reification and social acknowledgement, from Axel Honneth. That being said, the idea is to elucidate the existing relations between the claims of practice in teacher formation, put in practice on the last renovations of the educational field, and the possible protests about the reification on the educational process, as well as to study some possibilities of alternative propositions inspired on the idea of acknowledging each other. The proposal works to answer to the following questions: In what sense, does the official law of teacher formation (referring to the teachers of basic school), based on the conception of competences, convergesitself to the manifests of reification processes? How could it be created a new perspective of the intersubjective acknowledgement?

Keywords: Competences. Teacher formation. Philosophy of Education. Reification. Acknowledgement. 


\section{Notas}

1 Ver, a esse propósito, o texto de Mello (2000): Formação inicial de professores para a educação básica: uma (re)visão radical.

2 O sentido dessa expressão, aqui cunhada, pode ser compreendido melhor nas premissas da maiêutica socrática.

\section{REFERÊNCIAS}

BLOOM, Benjamin. Taxionomia dos objetivos educacionais. Porto Alegre: Globo, 1976.

BRASIL. Ministério da Educação. Conselho Pleno. Resolução CNE / CP 01/2002, de 18 de fevereiro de 2002. Institui as Diretrizes Curriculares Nacionais para a Formação de Professores de Educação Básica, em nível superior, curso de licenciatura, de graduação plena. Brasília, 2002.

Resolução CNE / CP $n^{\circ} 02$ / 2002. Institui a duração e a carga horária mínima obrigatória dos cursos de licenciatura, de graduação plena, de formação de professores da Educação Básica em nível superior. Brasília, 2002.

DALBOSCO, Claudio Almir. Reificação, reconhecimento e educação. Revista Brasileira de Educação, São Paulo, v. 16, n. 46, p. 33-49, jan./abr. 2011.

GADAMER, Hans-Georg. Verdade e método. Trad. de Paulo Meurer. Petrópolis, RJ: Vozes, 1997.

GOERGEN, Pedro L. Prefácio. In: FLICKINGER, Hans-Georg. A caminho de uma pedagogia hermenêutica. Campinas: Autores Associados, 2010. p. 9-22.

HONNETH, Axel. Luta por reconhecimento: a gramática moral dos conflitos sociais. São Paulo: Editora 34, 2003.

. Reificación: un estúdio enla teoria delreconocimiento. Buenos Aires: Katz, 2007.

. Observações sobre a reificação. Civitas, Porto Alegre, v. 8, n. 1, p. 68-79, jan/abr. 2008.

MELLO, Namo de. Formação inicial de professores para a educação básica: uma (re)visão radical. Em Perspectiva, São Paulo, SEADE, v. 14, n. 1, p. 98-110, jan./mar. 2000.

MACEDO, Elizabeth. Formação de professores e Diretrizes Curriculares Nacionais: para onde caminha a educação? Teias, Rio de Janeiro: ProPEd/UERJ, v. 1, n. 2, p. 1-16, 2000.

PERRENOUD, Phillippe. Construir as competências desde a escola. Porto Alegre: Artes Médicas, 1999.

ROUANET, Sérgio Paulo. As razões do Iluminismo. São Paulo: Companhia das Letras. 1988. 